\title{
Philosophiques
}

Jean Frère, Les Grecs et le désir de l'être. Des Préplatoniciens à Aristote. Paris, Les Belles Lettres, 1981, 462 pp.

\section{Richard Bodéüs}

Volume 16, numéro 1, printemps 1989

URI : https://id.erudit.org/iderudit/027074ar

DOI : https://doi.org/10.7202/027074ar

Aller au sommaire du numéro

Éditeur(s)

Société de philosophie du Québec

ISSN

0316-2923 (imprimé)

1492-1391 (numérique)

Découvrir la revue

Citer ce compte rendu

Bodéüs, R. (1989). Compte rendu de [Jean Frère, Les Grecs et le désir de l'être.

Des Préplatoniciens à Aristote. Paris, Les Belles Lettres, 1981, 462 pp.]

Philosophiques, 16(1), 206-208. https://doi.org/10.7202/027074ar d'utilisation que vous pouvez consulter en ligne.

https://apropos.erudit.org/fr/usagers/politique-dutilisation/ 
JEAN frère, Les Grecs et le désir de l'être. Des Préplatoniciens à Aristote. Paris, Les Belles Lettres, 1981, 462 pp.

\author{
par Richard Bodéüs
}

On sait le caractère intellectualiste de la morale chez les anciens Grecs et l'importance des apports chrétiens, spécialement augustiniens, dans l'élaboration du concept de volonté au cours de l'histoire.

Il ne faudrait pas sous-estimer, pour autant, la place accordée par les premiers philosophes de la Grèce à tout ce qui, dans l'âme, n'est pas raison ou

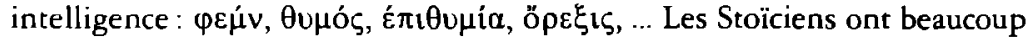
fait pour que l'on tînt tout cela pour l'ennemi à vaincre et à détruire. Mais une tradition antérieure, qu'ils n'ont jamais réussi à définitivement supplanter, y voyait aussi l'allié indispensable qu'il fallait s'adjoindre. C'est ce qu'entreprend de montrer ici J. Frère. Aristote, Platon et déjà les préplatoniciens, scrutant les désirs de notre âme, avaient reconnu l'importance de ce que Pascal, beaucoup plus tard, appellera «le cœur » et saisi, dans la soif de connaître, l'attirance d'un absolu que subit l'être humain tout entier.

Le mérite de cet ouvrage très documenté est de suivre à la trace, textes à l'appui, les efforts de la pensée grecque, des origines à l'époque classique, pour découvrir ce que d'aucuns imaginent qu'ils cherchaient à oblitérer : les valeurs positives de l'âme dite «irrationnnelle». J. Frère a pris soin de reconstituer les lignes d'une évolution sur fond de permanence. Auxillaire de la vérité et du bien, le désir multiforme occupe une place remarquable dès l'âge des présocratiques et des sophistes. Platon, à cet égard, est l'héritier de longues traditions, qui prennent place progressivement dans un système

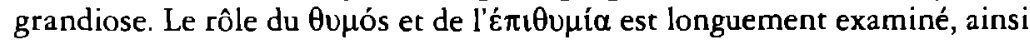
que leur rapport à l' $\varepsilon \rho \omega \varsigma$, qui sublime les appétits. Le prix qu'accorde Platon à la $\mu \alpha v i \alpha$ pour la découverte de la vérité est souligné à souhait, comme sont mis en lumière les sentiments qui, selon le philosophe, élèvent l'homme à la passion du juste. La dernière partie de l'ouvrage, à laquelle est ordonnée toute la recherche, montre comme Aristote, enfin, opère une synthèse de ses

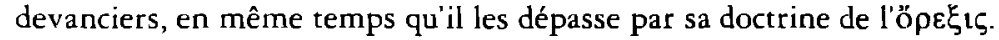

L'exposé que J. Frère consacre à la philosophie d'Aristote couvre tous les aspects de l'œuvre immense du Stagirite. Il vise à reconstituer les étapes au cours desquelles s'est élaborée la doctrine aristotélicienne du désir. Il s'inscrit de la sorte dans la catégorie des études «génétiques» qui, depuis un demi siècle, se sont efforcées de décrire l'évolution des thèses du philosophe. Mais $\mathrm{J}$. Frère s'attache moin à l'histoire de cette évolution supposée qu'à l'analyse des différents aspects d'une doctrine constituée. Et, à cet égard, la relecture qu'il fait de la plupart des grands textes d'Aristote, à l'affût des moindres allusions aux diverses formes d'ó $\rho \varepsilon \xi 1 \zeta$ considérées par le philosophe, est une relecture qui mérite toute notre attention. Elle aboutit à la mise en lumière de ce que l'auteur appelle une éthique et une métaphysique de l'affectivité et où c'est le système aristotélicien qui se trouve éclairé, abstraction faite de sa genèse. 
Une certaine fraîcheur dans le regard que J. Frère promène sur les Grecs, le dispense d'accumuler les signes, souvent fallacieux, de l'érudition. Je ne veux pas cacher ici le plaisir que jai eu à lire son ouvrage.

Département de philosophie

Université de Montréal 